\title{
La construcción discursiva de un genocidio en Colombia: una aproximación a la versión de las Fuerzas Militares en el caso de la Unión Patriótica
}

\author{
The discursive construction of a genocide in Colombia: \\ an approach to the version of the Military Forces in the case of the Patriotic Union
}

\author{
Liliana A. Silva Bello \\ Socióloga, Universidad Santo Tomás \\ Coordinadora de Planeación y Participación Ciudadana, Alcaldía Local de Fontibón \\ Miembro del Equipo Nacional de Constituyentes por la Paz con Justicia Social en Colombia \\ lilianandreasilva@gmail.com \\ Mauricio Poveda Pineda \\ Sociólogo y economista, Universidad Santo Tomás \\ Estudiante de la Maestría en Estudios Políticos y Sociales, \\ Universidad Nacional Autónoma de México \\ maopove46@hotmail.com \\ Artículo de investigación
}

Fecha de recepción: 17 de noviembre de 2010 • Fecha de aprobación: 19 de enero de 2011

\section{RESUMEN}

En la década de los ochenta, frente al conflicto político y social entre las guerrillas y el Estado colombiano; la Unión Patriótica se consolida como una alternativa negociada que rompe con el tradicional bipartidismo y comienza un importante ascenso electoral en todo el territorio nacional. Esto marcaría el principio de una de las más grandes olas de violencia política y represión que llevarían a su posterior exterminio. En este genocidio, las Fuerzas Armadas desempeñaron un papel preponderante tanto por su acción como por su omisión, pero también - y en particular para el interés de este trabajo- en la construcción de un discurso políticomilitar que identificó a la Unión Patriótica como un enemigo y legitimó su aniquilación.

Palabras clave: violencia política, Colombia, Unión Patriótica, discurso militar. 


\begin{abstract}
In the 80 s, during the political and social conflict between the guerrillas and the Colombian state, the UP grew and consolidated as a negotiated alternative different from traditional two parties. It also started to improve in the electoral landscape all over Colombia. Simultaneously, this was the beginning of one of the biggest waves of political violence and repression that would result in the extermination of this group. In the context of this genocide, the Armed Forces played an important role, by action and omission, and helped to construct a political discourse that described the UP as an enemy and consequently, they contributed to legitimize their annihilation.
\end{abstract}

Keywords: political violence, Colombia, Patriotic Union, military discourse.

\title{
ExClusión sociopolítica en Colombia
}

En el trascurrir de su historia política en la década de los años ochenta, Colombia tuvo una historia que la ha impulsado a desarrollarse en escenarios políticamente excluyentes y tendientes hacia la uniformidad ideológica, en la cual se hallan procesos institucionales, culturales, políticos, entre otros. Después de sucesos como el asesinato de Jorge Eliécer Gaitán, la presidencia del general Rojas Pinilla, la Junta Militar en la década de los años cincuenta, entre otros, se establecen procesos de reforma política de largo plazo a cargo de los partidos Liberal y Conservador, que negaron la posibilidad a un tercer elemento político que difiriera de las dinámicas implantadas hasta el momento.

Ante tal espectro, surgen tendencias institucionales organizativas y políticas; unas más radicales que otras, pero igualmente reformistas ante el escenario excluyente y absolutista por parte de las dos fuerzas presentes hasta el momento. Grupos como la Alianza Nacional Popular (Anapo) o el Movimiento Revolucionario Liberal (MRL) figuran como alianzas entre diferentes sectores de la política colombiana, en búsqueda de reformas y nuevos espacios, animados y formados por el descontento en el plano político nacional, e impulsados, a su vez, por el contexto sociopolítico latinoamericano de cambio, lucha y revolución. Paralelamente, el descontento y la 
falta de escenarios de participación política por las vías institucionales dieron paso a la génesis de grupos guerrilleros en diferentes zonas del país, como alternativa al modelo implantado e intentando entonces por la vía armada derrocar el poder bipartidista que hasta el momento imperaba.

Es así como en un escenario exclusivo de participación ciudadana surgen, en resistencia armada, grupos guerrilleros (Ejército de Liberación Nacional [ELN], Ejército Popular de Liberación [EPL], Movimiento de Resistencia Quintin Lame [MRQL], Fuerzas Armadas Revolucionarias de Colombia [FARC], entre otros) de variadas directrices ideológicas y reivindicativas, que reconfiguran, a partir de su nacimiento, el escenario social y político en las zonas en donde harían presencia. El grupo subversivo FARC hace su aparición en 1964, posicionándose como actor armado con fines políticamente establecidos en la lucha por la toma del poder, que durante ese momento lo detentaban la élites hegemónicas liberal y conservadora.

Finalizando la década de los años setenta, el país se encontraba sumergido en una gran lucha de confrontación y reconocimiento social y popular frente a un Estado que no satisfacía las demandas del sector social; reclamaciones que empezaban a encontrar cierta afinidad en los diferentes escenarios de los movimientos sociales (estudiantes, sindicalistas, trabajadores, campesinos, entre otros) y guerrilleros (FARCEP, ELN, M-19, EPL) y encontraban respuesta violenta por parte del Estado, el cual se fortalecía ideológica y militarmente en la represión de dichas manifestaciones y en la conservación de los objetivos de seguridad nacional.

Durante la historia de conflicto armado en el país, se posicionan luchas de carácter reivindicativo esencialmente en los sectores más desprotegidos por el Estado colombiano, en donde se ubica el sector rural y popular. Reclamaciones hacia la mejora en las condiciones de subsistencia y bienestar social hacen parte de un cúmulo de experiencias de represión, control y dominio por parte de la hegemonía institucional instaurada durante años. Tal carácter hegemónico ha logrado deslegitimar y obstruir salidas en procura de un Estado participativo como generador y garantista del bienestar colectivo en la sociedad colombiana, excluyendo de la escena a sectores sociales como estudiantes, sindicatos, indígenas, campesinos, negritudes, entre otros. 
Dicha extrapolación, como síntoma y reflejo del manejo del poder en Colombia, hizo posicionar históricamente, en la esfera pública global e institucional, al Estado colombiano como gran transgresor en la garantía y generación de los derechos humanos, al supeditar a la población a fenómenos como el desplazamiento forzado, la expropiación de tierras, la desaparición forzada, el genocidio político, el etnogenocidio, la persecución al pensamiento crítico, las ejecuciones extrajudiciales, entre otros. Tales violaciones, además de poner en vilo al sistema de la justicia colombiana, han sido legitimadas de una u otra manera, justificando su existencia y generando la configuración social de nuevos sistemas de valores basados en la exclusión como factor que ha generado representaciones sociales de estigmatización en los planos político, social y cultural. Estas representaciones han sido, y son, reflejo del dominio y monopolio del poder, donde tan solo algunos pocos acceden a los beneficios que genera un sistema basado en la exclusión y militarización de sus valores sociales históricamente consolidados.

\section{Surgimiento de la Unión Patriótica}

A finales de la década de los años setenta, el surgimiento de nuevas salidas dialogadas al conflicto armado que vivía el territorio colombiano enmarca el escenario en el que grupos alzados en armas, como el M-19 y las FARC-EP, inician los acuerdos con las fuerzas estatales para poner fin a las décadas de conflicto y guerra vividos en la sociedad colombiana.

Mediante el Acuerdo de los Diez Puntos, establecido en marzo de 1984, se presenta el carácter propositivo de las FARC-EP, el cual daría formación y génesis al partido político Unión Patriótica (UP) y generaría transición del movimiento guerrillero a la acción de masas y a la apertura democrática por medio del escenario parlamentario. A partir de los acuerdos se generaron compromisos tanto del Estado como de las FARC-EP, en aras de conseguir la anhelada paz. Por una parte, el Estado se comprometía a realizar reformar políticas, económicas y sociales, mientras el movimiento guerrillero se comprometía a regresar progresivamente a la vida civil por medio de los instrumentos políticos ofrecidos en el acuerdo, como la creación y participación de un nuevo partido político llamado UP. De igual manera, ambas 
partes asumían el compromiso de un cese bilateral del fuego y la búsqueda conjunta de una salida política al conflicto.

Aunque desde su nacimiento el movimiento político UP se posicionó como el producto de los acuerdos, este se configuró como un movimiento independiente del grupo insurgente; sin embargo, a raíz de las múltiples problemáticas generadas desde diferentes sectores sociales, el argumento sobre su origen presuntamente vinculado a la ilegalidad se utilizaría posteriormente para deslegitimar, estigmatizar y reprimir su accionar político y popular.

De esta forma, la UP hace su aparición formal en el escenario político el 28 de mayo de 1985, a través del Primer Congreso Nacional, en donde continúa con la lucha política por establecer la tregua e instaurar de manera incluyente sectores populares y políticos que reunieran las distintas insatisfacciones generadas durante ańos. Solicitaron al gobierno que se levantara el estado de sitio y se combatiera efectivamente a los grupos armados paramilitares, desmilitarizando las zonas en donde se presentaban los conflictos y generando un espacio que garantizara la supresión de la violencia como recurso de acción política tanto estatal como social y popular.

Establecido entonces el acuerdo y, con él, la formación y consolidación del partido UP, se proyectaban los escenarios para el posible logro consecutivo de la paz. Al respecto señala Ortiz (2007):

El objetivo de la paz no se desvanecía aún pese a las posiciones de las élites políticas, las FF. AA. y las acciones de los paramilitares; por eso, en 1985 se registra el nombramiento de Comisiones Regionales de Verificación de los Acuerdos.

Sin embargo, aunque el proceso de paz siguió su curso como la expresión máxima de que durante años no había logrado reunir las diferentes tendencias políticas en torno a la materialización de los ideales, el acuerdo en sí mismo contaba con grandes opositores de diferentes sectores institucionales, económicos, políticos y sociales, los cuales generaron presión no solo sobre la legitimidad de los acuerdos, sino también sobre la misma existencia de la UP. 
Tales inconformidades de sectores ligados al poder hegemónico se vieron reflejadas en el posterior exterminio o genocidio del partido UP. Puede partirse del hecho de que desde el principio de los acuerdos, mientras se negociaban, eran asesinados miembros de las organizaciones subversivas que estaban en tregua, al punto de que cuando dicho movimiento político se presenta a la contienda electoral ya habían sido asesinados aproximadamente trescientos de sus miembros (Ortiz, 2007, p. 17).

Uno de los mayores cuestionamientos al gobierno y a las propuestas del entonces presidente Betancur radican en que, como jefe máximo del Estado, no fue capaz de lograr que se legitimara institucional y socialmente la estrategia de diálogo por medio de los acuerdos firmados en la Uribe, si se tiene en cuenta que a su vez desde el mismo gobierno se habían implantado medidas represivas y soluciones militaristas en medio de los diálogos de paz.

Contraponiéndose a la propuesta de diálogo, la estructura institucional hegemónica colombiana cumplió un papel fundamental en la legitimación de la desaparición y genocidio del partido político UP en los años posteriores a su creación. Fenómenos de acción y omisión directa frente a los más de cinco mil asesinatos selectivos perpetrados durante la existencia y posterior desaparición parlamentaria del partido político involucran a diferentes sectores institucionales y gubernamentales de poder en Colombia ${ }^{1}$.

\section{DoCTRINA DE LA SEGURIDAD NACIONAL: INFLUENCIA Y DESARROLLO}

En medio del contexto de polaridad mundial en la década de los años setenta y ochenta, cuando se ponen en marcha mecanismos de control geoestratégico al servicio de las tendencias políticas e ideológicas marcadas por la guerra fría, se activaron herramientas de adoctrinamiento sociopolítico que orientaron el desarrollo y el establecimiento de patrones de control en diferentes naciones como Colombia. Uno de ellos, conocido como la Doctrina de Seguridad Nacional (DSN), configuró la generalización de

1 Al respecto véase el Informe 5/97, caso 11227 sobre admisibilidad, de la Comisión Interamericana de Derechos Humanos (1997), Corte Interamericana de Derechos Humanos, Sentencia del caso Manuel Cepeda Vargas, 26 de mayo de 2010 . 
nuevas representaciones sociales e ideológicas que enmarcaron la implantación de procesos de exclusión y exterminio frente a las consideradas amenazas que pudieran poner en riesgo el mantenimiento del orden.

La DSN puede ser considerada como una tendencia de control geopolítico y estratégico mundial: sentó sus cimientos principalmente en la década de los años sesenta, cuando la estructura militar va a desempeñar un papel decisivo para su efectiva consolidación frente a los fenómenos calificados como subversivos, que empezaban a visibilizarse durante esta época, especialmente en varios países de América Latina. A partir de allí, la seguridad nacional se reafirma como columna vertebral y necesidad primaria de los Estados que se vieran amenazados frente a los peligros globales. De esta manera, como expone Sohr (1991) en su análisis sobre la seguridad y la defensa, "la seguridad es una condición deseada universalmente por toda la población. Presentarse como el proveedor y custodio de la seguridad es hacerse acreedor al reconocimiento público" (pp. 17-24). Por tanto, la intervención de la DSN se convertiría, a su vez, en una característica fundamental de la lucha contra el enemigo, lo que empezaría a visibilizarse locamente en los países del cono sur.

En medio de tal estructura global, dirigida racionalmente por el elemento simbólico de la violencia como forma de hacer y defender la política y con apariencia de legalidad de un Estado de derecho, se asume en tal escenario el poder legítimo de la fuerza -y su componente institucional y militar con mayor fuerza-, posicionándose como institución relevante en la política colombiana: "Su inmersión en la nueva violencia política que retaba al sistema aceleró ese proceso y les permitió llenar el vació ideológico que se presentaba” (Leal, 1992).

El principal componente de la DSN, en Colombia, tiene en su plataforma a la institución militar como eje de dirección, donde desde diferentes escenarios se le otorgan elementos de poder para el establecimiento de tal doctrina. De esta manera, el Decreto 3398 de 1965, conocido como el Estatuto Orgánico de la Defensa Nacional, subordinó los cuerpos de seguridad del Estado al control de las Fuerzas Militares (Organización Mundial Contra la Tortura [OMCT] et al, 1992). Por otra parte, el surgimiento del Plan Laso (Latin American Security Operation), como parte de la estrategia contrasubversiva — como otros de los planes que hacen parte de las reproducciones de 
la DSN en el país_-, se convierte en uno de los planes más influyentes en Colombia, por su orientación marcadamente anticomunista que se logrará incorporar en la estructura militar colombiana. Leal (2006) lo explica del siguiente modo:

El objetivo de fondo era la erradicación del comunismo, pues se suponía que esta ideología propiciaba las guerrillas y la subversión, siempre y cuando existiera el caldo de cultivo de la pobreza (p. 64).

El Plan Laso es, entonces, uno de los más fuertes rezagos de la DSN en el país; sus prácticas violentas y altamente anticomunistas serían muy reconocidas en la institución castrense por sus aportes potencialmente ideológicos y simbólicos.

Es fundamental, por consiguiente, reconocer cómo en la realidad social colombiana la DSN permitió a la institución política y militar proyectarse con más fuerza, generando prácticas y acciones concretas que se reflejarían en las políticas de represión, estigmatización y señalamientos constantes a los diferentes sectores sociales del país, los cuales buscarán reivindicar y promover movimientos democráticos, pluralistas y participativos.

De igual forma, el anticomunismo como elemento cumbre en la DSN va a influir en gran medida la concepción del enemigo interno, lo que derivó en la tendencia de la estigmatización y diferenciación. Asimismo, el establecimiento sistemático y estructural de políticas doctrinales implementadas, al igual que sus rezagos, han ocasionado profundos daños al tejido social, ya que la vulneración a la integridad de los seres humanos se ha visto legitimada ampliamente por la misma institucionalidad hegemónica, por medio del uso de la violencia cuando el enemigo interno o la amenaza comunista se hace latente para el establecimiento y mantenimiento del orden social impuesto.

\section{Posicionamiento InSTITUCIONAL Y POLÍTICo DE Las Fuerzas Militares}

Las Fuerzas Militares (FF. MM.) de Colombia, en su recorrido histórico, se han caracterizado por ser protagonistas fundamentales en el proceso sociopolítico del 
país. Analizar la participación y formación que las FF. MM. han adquirido con el tiempo implica señalar algunas situaciones que indican la manera en que ellas se ha involucrado de manera muy particular en el escenario político nacional e internacional.

Vale la pena anotar que la creación y consolidación del ejército en función del Estado-nación se concibe a mediados del siglo XIX, cuando se observa un ejército carente de profesionalismo y autonomía como institución, formado al calor de las luchas de la guerra misma y cuya jerarquía se establecía a partir del padrinazgo político y los diferentes lazos de parentesco existentes en la sociedad de entonces. Solo hasta entrado el siglo XX se fomentan las bases jurídicas para el funcionamiento de las FF. MM. como un ejército en función del Estado centralizado y como garante del mantenimiento del orden permanente para la defensa de la nación, aunque sin carácter deliberante en la situación política nacional; sin embargo, la promoción y el padrinazgo dentro de la institución militar, en cuanto garante de ascensos y jerarquías, significó el casamiento con la clase política hegemónica, elemento que ha permitido que su acción político-militar se desarrolle en función de intereses partidistas y hegemónicos establecidos en el territorio nacional.

Teniendo en cuenta la consolidación de su papel dentro del espectro político colombiano, los militares fueron considerados por tendencias como la DSN como garantes permanentes en el control del aparato político estatal y del proyecto político integral de seguridad, encargados del mantenimiento y estabilidad del país (Blair, 1993).

A principios del siglo XX, los militares entran en la profesionalización militar como consecuencia de la creación de las escuelas superiores de guerra, lo que los convierte en actores politizados en la realidad del país, capaces de asumir la construcción nacional no como militares sino como actores vinculados a la defensa del poder estatal $^{2}$ (Tapia, 1988: 241).

2 La concepción de las fuerzas armadas como nation building, o constructoras de nación, es una teoría ampliamente desarrollada en los Estados Unidos tanto por sectores de cientistas sociales como por círculos y escuelas alrededor de estas fuerzas. 
Durante los años setenta se generarán diversas estrategias jurídicas que sustentarán la labor de apoyo de las FF. MM. en pro de la seguridad interna de América Latina. En Colombia, la implantación jurídica y reglamentada se da en 1974 a través del Decreto 1365 de la Seguridad Nacional, y en 1978 con el Decreto 1923, conocido como el Estatuto de Seguridad Nacional, a partir del cual se abre mucho más el espacio de acción coercitiva por parte de las fuerzas militares en el país y hacia su población. Con ello se configuró el caso más palpable, para Colombia, de aplicación de la DSN implantada para Latinoamérica: la defensa de los objetivos nacionales prima sobre cualquier otra dinámica política del momento, y se presenta la guerra antisubversiva como un elemento unificador de factores de dominio estatal; dinámica ejercida en el plano militar, político, económico y psicosocial.

Debido a instrumentos legales propios del Estado de sitio "por parte de las Fuerzas Armadas, en la década de los ochenta estas tomarán una relevancia sin precedentes y se constituirán en un actor de primer orden en la vida política nacional" (Tapia, 1998: 129). Durante este periodo se hará evidente la injerencia militar en el manejo del orden público, lo que deja ver el papel que habían llegado a desempeñar las FF. MM. en la sociedad: "El orden público también se relacionará con todas las protestas sociales, 'criminalizadas' por el gobierno por considerarlas base de la subversión y a las que se les va a tratar militarmente" (Tapia, 1998: 131).

De esta manera se otorga el manejo exclusivo militar de las problemáticas sociopolíticas a las FF. MM., consideradas como el adalid de la seguridad interna y garantes como institución de la estabilidad social del país, para lo cual contaban con el respaldo institucional y de algunos sectores, además de los recursos legales propios de un estado de excepción para desarrollar sus acciones. Así, las FF. MM. se configuran periódicamente como un ente estatal ampliado en sus atribuciones, como muestra de su autonomía militar en la injerencia del manejo del orden público y recrudeciendo su acción militar, con el fin de desterrar cualquier señal de comunismo, focalizada en los movimientos guerrilleros, bases subversivas, estructuras políticas, educativas, universitarias, rurales y urbanas.

De acuerdo con lo anterior, se puede denotar la manera en que las FF. MM. asisten legítimamente a escenarios en los que la política y la concertación democrática 
presentes en la resolución del conflicto armado generaron, en la institución castrense, incursiones ideológicas y políticas que transfiguraron el accionar y el horizonte hacia donde se dirigieron las FF. MM. colombianas en el desarrollo de historia.

\section{El disCURSO DE LAS FF. MM.: UNA HERRAMIENTA DE EXTERMINIO SISTEMÁTICO EN COLOMBIA}

En Colombia, la construcción del discurso político militar de las FF. MM. se ha convertido en un modelo trasversal a la estructura política. Esto ha servido como sustento para que la homogeneidad, el orden y el pleno rechazo a la diferencia y al conflicto en su conjunto sean características que permeen el plano de las relaciones sociales e institucionales.

En este sentido, puede pensarse un sistema de signos expresados en el lenguaje, frente a lo cual Berger y Luckman (2001) explican:

[El sistema de signos lingüísticos] objetiva las experiencias compartidas y las hace accesibles a todos los que pertenecen a la misma comunidad lingüística en lo que se convierte en base e instrumento del acopio colectivo de conocimiento (p. 89).

De acuerdo con este planteamiento, según el alcance social que tenga la relevancia de dicho esquema transmisor y productor de conocimiento y su complejidad e importancia en una colectividad particular, tal modelo tal vez "tendrá que reafirmarse por medio de objetos simbólicos y/o acciones simbólicas” (p. 95); pero también por procedimientos para que tales significados sean recordados y replicados, si fuese necesario, por medios coercitivos y, por lo general, desagradables, con el fin de que tales sucesos no sean prontamente olvidados y, por el contrario, tengan una recordación y legitimación prolongada a través del tiempo.

Lo anterior nos permite situar a las FF. MM., desde su institucionalidad, como agentes que históricamente han configurado importantes elementos en la construcción de representaciones e imaginarios sociales dentro de la conciencia colectiva de los 
colombianos. Por ende, hablar del discurso político militar de las FF. MM. convierte a la DSN, a la lucha contrainsurgente y a toda la avanzada anticomunista en Colombia en elementos presentes en las dinámicas de reproducción del lenguaje, en el ejercicio de instrumentalizar la legitimidad de su institución castrense desde acciones directas contra ciertos sectores de la sociedad colombiana.

\section{Tres MeCANISMOS DE LEgITIMACIÓN DEL DISCURSO DE LAS FF. MM.}

La UP, como corriente que reunía múltiples sectores de la sociedad colombiana, visible como partido opositor de la década de los ochenta, va a ser uno de los principales focos de acción directa y de persecución constante desde el discurso de las FF. MM., como una estrategia para legitimar ante la sociedad colombiana una arremetida dirigida a la eliminación sistemática de sus militantes en las diferentes regiones del país.

En primer lugar, el elemento de la democracia liberal va a ser uno de los ejes verticales presentes en el discurso de las FF. MM., como reflejo de las creencias ancladas en los valores y mecanismos tradicionales de la paz, la armonía, el control y del pleno rechazo al conflicto. Con ello se desata claramente la concepción del enemigo como aquel que desvirtúa en cualquier sentido el modelo hegemónico que plantea la democracia liberal para las sociedades.

Fundamentalmente, la categoría de la democracia liberal responde, entonces, a los mecanismos por los cuales las diversas construcciones de sentido y de significado en la historia de la democracia, desde una concepción occidental, se han caracterizado por el ejercicio pleno del orden y de la homogeneidad que va a ser reflejo del poder de los Estados. Este poder es ejercido a partir de la justificación de los valores universales y abstractos de la ilustración, regidos bajo los lineamientos de la uniformidad racional del hombre y de la negación de la pluralidad social, cultural y política existente en las sociedades.

Un claro ejemplo práctico que orienta la democracia liberal, desde la discursividad castrense, corresponde al siguiente apartado pronunciado por el capitán Luis Alberto Villamarín (1990): 
El bandolerismo politizado que azota el país consta de dos elementos perfectamente definidos, a los cuales denominan tareas de carácter políticomilitar. La teoría marxista-leninista cataloga a nivel general dichas partes como la vanguardia y la retaguardia del proceso revolucionario, que lleva las masas a la construcción del socialismo, la eliminación del capitalismo y la dictadura del proletariado, ahora denominada "poder popular revolucionario". Los detentores del desorden y la violencia marxista-leninista orientan la lucha revolucionaria desde los dos ángulos (p. 103; las cursivas son agregadas).

Dicha afirmación no solo responde a una reflexión militar, sino que a su vez hace parte de toda una maquinaria discursiva que representa políticas estatales materializadas en construcciones sociales, en las que confluyen diversos actores de la sociedad colombiana catalogados como enemigos y amenazas a causa de sus concepciones comunistas o revolucionarias. Elementos como estos son un vehemente reflejo de las aplicaciones de la DSN Colombia, en cuanto un sólido mecanismo para el señalamiento de ciertos sectores que irrumpen con el modelo capitalista tradicional, el orden social establecido y, por ende, el carácter democrático en su concepción clásica liberal que caracteriza a las FF. MM. y al Estado colombiano.

El segundo elemento que subyace en la construcción discursiva de las FF. MM. con relación a la UP es el de enemistad, entendido como la configuración del enemigo desde el plano de lo político y de lo moral.

Es importante señalar la forma en que se establecieron adjetivos y calificaciones de carácter negativo ante la posibilidad de un pluralismo político que rompiera la hegemonía que durante años venía manejando la estructura política del país. Se caracteriza de esta manera como "enemigo político" al desarrollo generalizado de las actividades sociales y políticas que desplegaban la UP a nivel nacional, popular y parlamentario.

La legitimidad de las FF. MM. en relación con el ambiente político del momento es un componente desde el cual se lograron generar criterios de validez respecto al poder y accionar contrario de la institución castrense establecido en el momento, a pesar de que el gobierno de Belisario Betancur dispusiera instrumentos políticos 
y democráticos para el establecimiento de la paz y el desarme de la guerrilla de las FARC. Esto se constituía como elementos de negación puntual al trabajo político que pudiera llegar a desarrollar la UP, relacionando con su accionar político y la evolución y estrategia armada de las guerrillas presentes entonces en Colombia:

No se trata, pues, como se ha aducido en otros casos, de actitudes díscolas de subalternos guerreristas, sino de órdenes de quienes invocaron la paz, fundaron un partido de pantalla para que los represente y jamás pensaron en nada distinto de reanudar hostilidades una vez hubiesen sacado del fementido convenio todas las ventajas posibles (Valencia, 1987: 5).

Se establece, entonces, el desarrollo — en términos de Schmitt (1932)— de fronteras entre amigos y enemigos, convirtiendo en este caso a la UP en un intenso enemigo político, con lo que esta relación dirigida se amplía, con base en la enemistad, hacia el interior de la nación y, más específicamente, hacia el interior de la institución militar. Esto otorgó un carácter peyorativo en la escena social y política colombiana, y logró, de esta manera, caracterizar de forma negativa la existencia y nacimiento del nuevo partido político en contienda.

Se puede observar, en el análisis, que la expresión de lo político bajo lineamientos morales fue ejercida constantemente por la institución castrense en escenarios de carácter democrático, en los cuales, en lugar de ser catalogado tal adversario bajo categorías políticas, se estableció en términos morales su existencia y confrontación dicotómica entre lo "bueno y lo malo".

Con referencia en lo anterior, se observa que dicho desarrollo y utilización inadecuada de la moralidad imposibilitó los mecanismos de aceptación social y debate en términos políticos frente a la UP, y con ello se estipula una definición moral del adversario, en donde tal actor no pudo ser legítimamente reconocido, sino que, por el contrario, se convirtió en un enemigo "maligno" que debía ser destruido. Una de las características fundamentales expresadas por Mouffe (2007a: 10) es la expresión de lo político desde los lineamientos morales, que constantemente son ejercidos en escenarios que se denominan democráticos: 
En otras palabras, aun consiste en una discriminación nosotros/ellos, pero el nosotros/ellos, en lugar de ser definido mediante categorías políticas, se establece ahora en términos morales. En lugar de una lucha entre "izquierda y derecha" nos enfrentamos a una lucha entre "bien y mal" (p. 12).

Un claro ejemplo de esta moralidad de la enemistad corresponde al siguiente fragmento señalado por Guerrero (1989):

Porque en las actuales circunstancias de la nación, los oficiales que se han identificado con la savia fecunda de las lecciones del instituto constituyen el soporte fundamental para enfrentar los embates de la subversión, del narcotráfico y de todos los gérmenes de descomposición que amenazan tan altanera como cruelmente el régimen democrático del Estado colombiano (p. 5).

La moralidad de la política no solo pone en peligro la democracia en todo su espectro, sino que va a impedir un desarrollo de la lucha agonística planteada por Mouffe, con lo que se coartan las posibilidades de reconocimiento legítimo de la diferencia del otro. Así, se da paso a una definición rígida y casi inamovible de enemistad en escenarios homogéneos de rechazo colectivo a ciertos sectores que sean señalados como "malos", en contraposición con el sector correspondiente de los "buenos" que será aceptado socialmente.

En tercer lugar, el elemento de legitimación de la violencia reflejado en la caracterización del discurso político militar va a ser también una constante en la consolidación de representaciones sociales, que configurarían un universo de aceptación en la sociedad colombiana, de frente a la aniquilación sistemática del partido político Unión Patriótica. Dicha legitimación va a tener previamente una construcción de enemistad como condición primera que justifique el uso mismo de la fuerza. De este modo, la violencia resulta ser, entonces, un elemento articulador sustentado en el ejercicio de haber señalado previamente un adversario.

No obstante, el enemigo ya definido tiene que estar públicamente presente en la sociedad misma, pues el accionar del Estado como soberano puede disponer de diversos instrumentos que respondan con el ataque o la eliminación de esa amenaza latente, 
previamente edificada y sustentada bajo la premisa del desequilibrio al control generalizado del orden y la seguridad de los conciudadanos. En este sentido, el instrumento de poder va a ser legítimo cuando se genere una aceptación como generalidad que determine que dicho uso de la violencia sea completamente necesario. Según lo anterior, un ejemplo del uso de la legitimación de la violencia desde el discurso castrense se puede visibilizar con el siguiente fragmento, en el que el ministro de Gobierno Carlos Lemos Simmonds (2010), durante el periodo de Virgilio Barco, enuncia:

\begin{abstract}
El país ya está cansado, y una prueba de ese cansancio es que en estas elecciones votó contra la violencia y derrotó al brazo político de las FARC que es la Unión Patriótica. Se van a enojar porque les estoy diciendo esto, pero ellos saben que es así.
\end{abstract}

Al justificar las acciones violentas de manera generalizada contra la UP no solo se está afirmando categóricamente la derrota del brazo político de las FARC, sino que el discurso militar plantea toda una apertura a la persecución y exterminio del partido político, como acciones de aprobación que muestran que efectivamente el país está cansado de la violencia y, por ende, de la subversión. Se afirma, entonces, que la derrota de la UP es una muestra de legitimidad de la violencia aprobada de manera generalizada. Allí, al establecer una definición clara de enemigo político, no solo se justifica su derrota, sino que a su vez se va a legitimar el genocidio político de sus dirigentes y militantes del partido, al ser definidos como aliados del brazo armado y de las causas que generan violencia en el país, y que, por tanto, deben desaparecer en nombre del bien común de la nación.

\title{
Conclusiones
}

El reflejo generalizado de la construcción de características trasversalmente presentes en las dinámicas discursivas de las FF. MM. en Colombia no solo permite encubrir y legitimar socialmente acciones criminales y organizadas en contra de la UP, sino que también, como agentes garantes de la seguridad de los ciudadanos y ciudadanas, son responsables por la acción y omisión de uno de los mayores genocidios en la historia de Colombia. Por su parte, se puede asegurar: 
En varias regiones de Colombia —Urabá, Meta, Antioquia, Santander, Arauca, Cundinamarca - la UP logró representación en los consejos y asambleas, y por primera vez en la historia de los movimientos políticos de izquierda en Colombia alcanzó una significativa representación en el Congreso de la República. Perdió su personería jurídica en el año 2000 tras el asesinato de miles de sus miembros y dirigentes, incluyendo dos candidatos presidenciales y buena parte de su representación parlamentaria (Colectivo de Abogados José Alvear Restrepo, 2010).

Por otro lado, en relación con el gobierno de Álvaro Uribe Vélez se puede asegurar que

Se han perpetrado, por lo menos, 136 homicidios contra los sobrevivientes de la Unión Patriótica y el Partido Comunista Colombiano (PCC), 38 casos de desaparición forzada y 28 intentos de homicidio. Esto sin contar con las cientos de familias desplazadas y víctimas de montajes judiciales. Pese a estos graves hechos, las autoridades no adoptaron medidas efectivas para prevenir nuevas violaciones (p. 86).

Dentro de los discursos político-militares se concluye que la apreciación de la institución militar frente a la UP se dirigía a entender al partido político no solo desde el plano de la desmovilización y participación política parlamentaria, sino que tal partido fue entendido como un movimiento político y popular de carácter negativo y amenazante hacia el orden establecido, capaz de dirigir sus acciones, deslegitimadas por la institución militar, hacia amplios niveles de la sociedad, logrando la trasformación del modelo tradicionalmente democrático constituido en el país.

De esta manera, el análisis del discurso político militar de las FF. MM. de Colombia, con relación al partido político de oposición UP, permite de manera acertada afirmar que efectivamente, dentro de un contexto más holístico de la sociedad colombiana entre los años 1987-1990, la constitución de la democracia liberal y tradicional colombiana fue el eje inquebrantable para impedir el desarrollo político y social de un partido político opositor con propuestas trasformadoras y 
cambiantes posibles para el país. Esto se enmarcó claramente en la explicación sustentada del establecimiento del orden social del poder hegemónico vigente y bipartidista, construido y fortalecido bajo la figura del enemigo como elemento de amenaza al statu quo predominante e indistintamente homogéneo.

Se puede concluir también que el sistema democrático colombiano, inscrito bajo unas lógicas unificadas y centralizadas en las esferas del poder político, ha tenido como eje trasversal la negación generalizada de la pluralidad política y social, como elementos indispensables en la trasformación y desarrollo de las estructuras democráticas convencionales. Esta negación implica el desconocimiento de múltiples expresiones y reivindicaciones de diversos sectores sociales que se fundamentan en la diferencia como un instrumento posibilitador de la creación de nuevos escenarios en los que tales sectores puedan confluir y construir nuevos lenguajes, en función de hacer posible la aparición de múltiples perspectivas y formas de comprender la realidad social no únicamente desde un vértice unidireccional e inamovible, no desde los postulados de la homogeneidad y del pensamiento racional y abstracto del universalismo clásico. Solo entonces se podrá hablar de una historia reconstruida desde el pleno reconocimiento por el otro, y no desde el aniquilamiento físico y moral que se ha venido incorporando durante décadas en Colombia, como una práctica regular e inherente al sostenimiento de la estructura política, social y cultural de nuestras sociedades resistentes a la trasformación y al cambio social. Por eso, la posibilidad de recorrer caminos alternativos que han planteado nuevas perspectivas en el país sitúa, en esencia, la posibilidad de estructurar la multiplicidad de existencias como un verdadero sentido para construir genuinas colectividades desde una democracia ampliamente pluralista.

\section{REFERENCIAS}

Berger, P. y Thomasm L. (2001). La construcción social de la realidad. Madrid: Amorrortu.

Blair, E. (1993). Las Fuerzas Armadas, una mirada civil. Bogotá: Centro de Investigación y Educación Popular. 
Colectivo de Abogados José Alvear Restrepo (2010). Colombia ante la Corte IDH por asesinato de senador Manuel Cepeda Vargas. Recuperado de http://comunidades.semana. com/wf_InfoNoticia.aspx?IdNoticia $=4068$

Comisión Interamericana de Derechos Humanos (1997). Informe n. 5/97, Caso 11227.

Corte Interamericana de Derechos Humanos (2010). Sentencia Caso Manuel Cepeda Vargas.

El Espectador (2009). Revive el caso de Bernardo Jaramillo. Recuperado de: http://www.elespectador.com/impreso/judicial/articuloimpreso173433-revive-el-caso -de-bernardo-jaramillo

Fuerzas Armadas de Colombia (1987, enero-diciembre). Periódico de las Fuerzas Armadas. Bogotá: Imprenta de las Fuerzas Armadas de Colombia.

Fuerzas Armadas de Colombia (1989, abril-junio). Revista de las Fuerzas Armadas. Bogotá. Imprenta de las Fuerzas Armadas de Colombia.

Fuerzas Armadas de Colombia (1990, octubre-diciembre). Revista de las Fuerzas Armadas. Bogotá: Imprenta de las Fuerzas Armadas de Colombia.

Leal Buitrago, F. (1992). El oficio de la guerra, La seguridad nacional en Colombia. Bogotá: Tercer Mundo Editores.

Leal Buitrago, F. (2006). La inseguridad de la seguridad. Bogotá: Planeta.

Mouffe, C. (2007a). En torno a lo político. Bueno Aires: Fondo de Cultura Económica.

Mouffe, C. (2007b). Prácticas artísticas y democracia agonistica. Barcelona: Museu d'Art Contemporani de Barcelona, Univeristat Autónoma de Barcelona.

Organización Mundial Contra la Tortura (OMCT) et al. (1992). Terrorismo de Estado en Colombia. Bruselas: NCOS. 
Campos en Ciencias Sociales

Comunidad, acción y comunicación

Ortiz Palacios, I. (2007). El genocidio politico contra la Unión Patriótica: visto por la prensa escrita 1984-2004. Bogotá: Universidad Nacional.

Reiniciar (2006). Tejiendo la memoria de una esperanza: Unión Patriótica. Bogotá.

Schmitt, C. (1932). El concepto de lo politico. Madrid: Alianza.

Tapia, J. (1998). La doctrina de seguridad nacional y el rol político de las Fuerzas Armadas. En El estado periférico de Juan Carlos Rubinstein. Buenos Aires: Tercer Mundo Editores. 